\title{
Shifty Operators in Changing Contexts
}

\author{
Pranav Anand \& Andrew Nevins \\ Massachusetts Institute of Technology
}

\section{Indexicals that Refer to Embedded Contexts}

It's fair to say that the study of indexicality has been primarily occupied with answering one question: Why are certain elements $-I$, you, yesterday - opaque to modal quantification? Indeed, Kaplan (1977), the most celebrated theory of indexicality, is designed precisely to answer this question: indexicals are rigidly specified once the character of a sentence is applied to the utterance context, before the content is derived. And yet, recent work in a variety of languages (e.g., Aghem (Hyman 1979), Amharic (Schlenker 2003), and Navajo (Speas 1999)) has recently converged on the general conclusion that this central empirical claim of indexical research was too hasty. That is, in some cases in these languages, sentences with the form John said that I am hungry may report John's self-report of hunger.

Based on data from two additional "indexical-shifting" languages, Zazaki ${ }^{1}$ and Slave, ${ }^{2}$ we argue that the interpretive possibilities of shifting indexicals are highly constrained. Our data come from three environments: cases with more than one embedded indexical, cases with different types of attitude verbs, and cases with more than one embedded speech-report. These data give rise to two interesting restrictions on indexical interpretation:

(1) a. Shift-Together: The indexicals in Zazaki and Slave show shifting under certain modal verbs, but cannot shift independently.

b. Within-language variation in indexical shifting: In Slave, the same indexical shifts obligatorily, optionally, or not at all, depending on the modal verb it is under.

We account for these puzzles by proposing that (at least in Zazaki and Slave) indexical shifting is driven by context-shifting operators, which overwrite the context parameter of the interpretation function with the intensional index parameter:

(2) CONTEXT-SHIFTING OPERATORS

a. Zazaki: $\llbracket \mathrm{OP}_{\forall}[\alpha] \rrbracket^{c, i}=\llbracket \alpha \rrbracket^{i, i}$

b. Slave: $\llbracket \mathrm{OP}_{\mathrm{AUTH}}[\alpha] \rrbracket^{\left\langle A_{c}, \ldots\right\rangle, i}=\llbracket \alpha \rrbracket^{\left\langle A_{i}, \ldots\right\rangle, i}$ 
This approach can be evaluated against Stechow (2002), Schlenker (2003) based on cases of multiple-embedding, where our operator-theoretic approach predicts that shifting within the intermediate clause prevents indexicals in the lowest clause from being indexical to the utterance.

(3) THE CASE OF MULTIPLE EMBEDDING

a. $\mathrm{C}_{A}\left[\ldots \operatorname{modal}_{1} \mathrm{C}_{B} \ldots\left[\ldots \operatorname{modal}_{2} \mathrm{C}_{C} \ldots\left[X P \mathrm{i}_{\{A, B, C\}}\right]\right]\right.$

b. $\quad \mathrm{C}_{A}\left[\ldots \operatorname{modal}_{1} \mathrm{C}_{B} \ldots\left[\ldots \mathbf{i}_{B} \ldots \operatorname{modal}_{2} \mathrm{C}_{C} \ldots\left[\mathrm{XP}_{\mathrm{P}} \mathrm{i}_{\left\{{ }^{*} \mathbf{A}, B, C\right\}}\right]\right]\right]$

We argue that the operator-theoretic approach better accounts for the puzzles in (1) than the other proposals that have been presented in the literature.

\section{The Shift-Together Constraint}

We begin by introducing the central empirical generalization for languages that allow indexical shift in embedded contexts: all indexicals within a speech-context domain must shift together.

\subsection{Indexicals shift in Zazaki}

All indexical expressions in Zazaki are in principle shiftable. That is, the Zazaki counterparts to English I, you, here, and yesterday all have the option of shifting when within the scope of the verb vano (meaning 'say'). ${ }^{3}$ This is illustrated for the first person, second person, temporal, and locative indexicals in the following four examples.

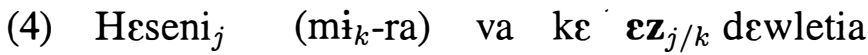

Hesen.OBL (I.OBL-to) said that I rich.be-PRES

'Hesen said that $\{\mathrm{I}$ am, Hesen is $\}$ rich.

(5) $\mathrm{Heseni}_{j} \quad\left(\mathrm{Ali}_{k}\right.$-ra) va $\mathrm{ke} \quad \mathbf{t i}_{j / k}$ dewletia

Hesen.OBL (Ali.oBL-to) said that you rich.be-PRES

'Hesen said that $\{$ Ali is, you are $\}$ rich.

(6) Waxto $\mathrm{k} \varepsilon$ ma D.-de bime, $\mathrm{H}$. mi-ra va $\mathrm{k} \varepsilon$ o ita ame dina When that we D.-at were, H.obl me-at said that he here came world 'When we were in Diyarbekir, Hesen told me he was born $\{$ here, in D.\}'.

(7) Hefte nayeraraver, $\mathrm{H}$. mi-ra va $\mathrm{k} \varepsilon$ o vizeri Rojda paci kerd. week ago, H.obl me-at said that he yesterday Rojda kiss did 'A week ago, $\mathrm{H}$. told me that he kissed Rojda $\{8$ days ago, \#yesterday $\}$.' 
The attentive/skeptical reader may object that these examples do not illustrate indexical shift, but rather are instances of direct quotation; that is, what we are seeing is something like Hesen said, "I am rich.". This explanation will hold little water in Zazaki. First, the examples with shifted here and yesterday $(6,7)$, which have an attitude-holder-referring 3rd-person pronoun cannot be direct quotation. No instance of direct quotation looks like Hesen said, "He $_{h}$ was born here."

Moreover, assuming that direct discourse is treated like a phonological string by the syntax of the embedding clause, it should be opaque to the grammatical processes of the embedding clause, and vice versa (Partee 1973, Recanati 1999, Schlenker 1999). However, we find that in Zazaki, there can be grammatical dependencies between the matrix and embedded clauses.

First, NPIs within a shifted context can be licensed by a matrix licenser, contrary to expectation if these are cases of direct quotation. For example, consider the word kes 'anyone,' which is an NPI in Zazaki.

(8) Mi kes paci *(ne) kerd

I.ERG anyone kiss *(not) did

'I did *(not) kiss anyone.'

kes can be licensed in an embedded clause with shifted indexicals by a matrix negation:

(9) Rojda ne va ke mi kes paci kerd

Rojda not said that I anyone kiss did

'Rojda didn't say that she kissed anyone.'

Since we know that "I kissed anyone" is not a grammatical sentence in Zazaki, (9) cannot be a quotation. Further evidence that these embedded clauses are not quotations comes from $\mathrm{A}^{\prime}$ extraction, which is illicit in bona fide cases of direct discourse:

* The girl that Hesen said,"I kissed $t$. ." is pretty.

However, A'-extraction is possible out of complements of vano with shifted indexicals:

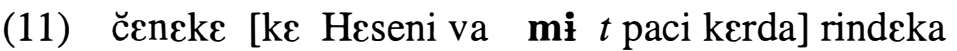
girl that Hesen said I $t$ kiss did pretty.be-PRES

'The girl that Hesen said $\{$ Hesen, I\} kissed is pretty.' 
(12) Piyaa-o [ke Rojda va $\mathrm{k} \varepsilon$ mi $t$ paci kerd] Ali biyo Person that Rojda said that I $t$ kiss did Ali was

'Ali was the person that Rojda said \{Rojda, I\} kissed.'

We conclude that the embedded clauses under scrutiny in Zazaki constitute a genuine case of indexical shift, to be accounted for by the grammar of referential interpretation.

\subsection{A constraint on shifting}

Consider again the examples of Zazaki shifting in (4-7). Each example contains two contexts of speech, the utterance context, $\mathrm{c}^{*}$, and the reported speech context. As we have seen, Zazaki indexicals are free to pick up reference from either context, and (4-7) are two-ways ambiguous. In principle, then, the introduction of an additional indexical should render these sentences four-ways ambiguous. However, they are not; speakers systematically exclude interpretations where the two indexicals pick up reference from different contexts:

Vizeri Rojda Bill-ra va $k \varepsilon \quad$ ez to-ra miradiša Yesterday Rojda Bill-to said that I you-to angry.be-PRES

'Yesterday Rojda said to Bill, "I am angry at you."

'Yesterday Rojda said to Bill, "AUTH( $\left.\mathrm{c}^{*}\right)$ is angry at $\operatorname{ADDR}\left(\mathrm{c}^{*}\right)$. ."

"*Yesterday Rojda said to Bill, "AUTH( $\left(\mathrm{c}^{*}\right)$ am angry at you."

"*Yesterday Rojda said to Bill, "I am angry at ADDR(c*)."

(14) Hesen mí-ra va ke ez nika $\{$ uža, *ita $\}$ ena Hesen me.OBL-to said that I now \{there, *here coming

'Hesen told me that he is coming here now.'

(15) Hesen hefti nayeraver reyal keno va $k \varepsilon$ ez to de hefti naeratepia Hesen week ago plan did said that I you two weeks after paci kena kiss will-do

A week ago, Hesen planned: "I will kiss you in two weeks." (not two weeks from now)

The important generalization that governs the interpretation of indexicals in the complement of vano can be schematized as follows: 


\section{(16) SHIFT-Together CONSTRAint}

All indexicals within a speech-context domain must pick up reference from the same context. ${ }^{4}$

a. $\mathrm{C}_{A}\left[\ldots \operatorname{modal} \mathrm{C}_{B} \ldots\left[\mathrm{i}_{\left\{\begin{array}{l}A \\ B\end{array}\right\}} \ldots \mathrm{i}_{\left\{\begin{array}{l}A \\ B\end{array}\right\}}\right]\right]$
b. $* \mathrm{C}_{A}\left[\ldots \operatorname{modal} \mathrm{C}_{B} \ldots\left[\mathrm{i}_{\left\{\begin{array}{l}A \\ B\end{array}\right\}} \ldots \mathrm{i}_{\left\{\begin{array}{l}B \\ A\end{array}\right\}}\right]\right]$

\subsection{Shift-Together also holds in Slave}

The Athapaskan language Slave also allows indexical shifting, subject to several interesting constraints which we will return to in section 4. For now, it suffices to observe that under the verb hadi 'he says', only 1st person indexicals shift (such examples are clearly not reducible to direct quotation, based on the behavior of 2 nd person):
Simon [rásereyineht'u] hadi
Simon [2.sg-hit-1.sg] 3.sg-say
Simon said that you $(\operatorname{ADDR}(U))$ hit him.

Like Zazaki, Slave respects SHIFT-TOGETHER: the possessor of the friend and of the slippers in the following example must be the same person, the embedded author.

[sehlégé segha gon'ihkie rárulu] yudeli
[1.sg-friend 1.sg-for slippers 3.sg-will-sew] 3.sg-want-4.sg

She $_{j}$ wants her friend to sew slippers for her $_{j}$

\subsection{Accounting for the constraint in Previous Theories}

Indexical shifting has been observed in a variety of languages over the past two decades: Aghem (Hyman 1979), Amharic (Leslau 1995, Schlenker 2003), Navajo (Speas 1999). To our knowledge SHIFT-TOGETHER has not been tested in this literature. ${ }^{5}$ Recently, two proposals have been advanced to explain indexical shift, the lexical underspecification approach of Schlenker (2003) and the feature deletion under binding approach of Stechow (2002).

Schlenker (2003) adopts an extensional semantics in which modal verbs quantify over contexts (i.e., include coordinates for speaker and hearer coordinates, in addition to those for world and time), and hence may bind free context variables in 
the syntax. Cross-linguistic differences in indexical shifting possibilities are localized to whether the denotations of particular indexicals have free context variables or not, as illustrated in the somewhat simplified examples below. ${ }^{6}$

(19) Indexical denotations for Schlenker (2003)

a. English ' $\mathrm{I}$ ': $\llbracket I \rrbracket=\operatorname{AUTH}\left(\mathrm{c}^{*}\right), \mathrm{c} *$ the context of utterance.

b. Amharic 'I': $\llbracket I \rrbracket=\operatorname{AUTH}(\kappa), \kappa$ a context variable.

Like Schlenker, Stechow (2002) handles indexical shift though binding by modal. quantifiers, which quantify over centered world-time tuples (i.e., over elements in the domain of the context). Cross-linguistic variation is a product of whether binding requires phi-featural identity: non-shifting languages allow a person indexicals to be bound only by attitude verbs agreeing in person, while Amharic allows binding of 1 st person indexicals, regardless the phi-features of the binding attitude verbs. Nevertheless, the semantic consequences of binding are universal - binding allows the deletion of semantic features of the bound element. Stechow justifies this universal on the basis of an example of presupposition deletion under binding by only I, attributed to Heim:
a. 'Only I did my homework.' [Only I] $\lambda x . x^{1 \text { st }}$ did $x^{1 \text { st }}$ 's homework.
b. shifted ' $I$ ': John says $\lambda\langle\mathrm{x}, \mathrm{w}, \mathrm{t}\rangle \mathrm{x}^{4 \text { st }}$ is a hero.

(20a) gives Stechow's logical form for the interpretation "I am the only person who did his homework.", where the first-person presuppositional content of my is not interpreted. Similarly, the first-person feature in (20b) is also deleted, allowing the indexical $I$ to be interpreted as John, the author of the reported speech act.

Neither Schlenker's nor Stechow's solutions predict the restriction on shifting in (25), since both proposals deal with each indexical independently. However, given that they both account for indexical shifting in terms of binding, it might be argued that the SHIFT-TOGETHER data presented above is actually a reflection of a restriction on crossing binding paths akin to the Oneric Reference Constraint (ORC) observed by Percus and Sauerland (2002). However, first note that the nested path interpretation (i.e., the fourth interpretation in (13)) should be available, contrary to fact. More directly, the SHIFT-TOGETHER constraint still holds even when the two items are not in a c-command relationship; the same is not true of the ORC.

(21) Hesen va $\mathrm{k} \varepsilon$ [pyaay $\mathrm{k} \varepsilon$ mi-ra hes kene] [pyaay $\mathrm{k} \varepsilon \mathrm{mi}-\mathrm{ra}$ hes Hesen said that [people that me.OBL like do] [people that me.OBL NEG, ne kene] ame zuja

like do] came together 
'H. said that people that like me and the people that don't like me met' 'H. said that the people that like $\operatorname{AUTH}(\mathrm{U})$ and the people that don't like AUTH(U) met'

* 'H. said that the people that like me and the people that don't like AUTH(U) met'

* 'H. said that the people that like $\mathrm{AUTH}(\mathrm{U})$ and the people that don't like me met'

While they cannot appeal to pre-existing principles to explain SHIFT-TOGETHER, the binding theories could be strengthened by stipulating it as a restriction on binding.

(22) Constraint on Shifting (proposed addition to Schlenker and Stechow):

All indexicals within the same modal-domain must be bound by the same context.

In the following section, we will advance a proposal that accounts for SHIFTTOGETHER without this sort of stipulation. The proposal is like Stechow's is placing the full responsibility for shifting in the hands of the attitude verb. However, like Schlenker, we will argue that cross-linguistic difference is lexically-determined (and not a matter of language-specific binding principles), though not by the indexicals themselves, but a limited series of context-shifting operators.

\section{Analysis: Operators that Change Context Variables}

\subsection{The Main Proposal}

Kaplan's (1977) classic theory of context dependence reduced the context of utterance to a formal tuple of various speech-act parameters (e.g., speaker, time of utterance, place of utterance, etc.), which, upon application of the character of an utterance, yielded a proposition. Kaplan's insights are standardly re-cast in compositional intensional semantics by specifying the evaluation function with both a context parameter and an index parameter (see Zimmerman (1991) for discussion). The index parameter does the work of the intensional semantics, storing the current world-time of evaluation, and can be changed by modal quantification.
a. $\llbracket \alpha \rrbracket^{\text {context, index }}$
b. 【say $\alpha \rrbracket^{c, i}=\lambda x_{e} . \forall j$ compatible with what $\mathrm{x}$ says in $\mathrm{i}, \llbracket \alpha \rrbracket^{c, j}$. 
The context parameter, however, is not affected by modal quantification, and hence expressions that depend on it are never affected by a modal quantifier; these comprise the set of indexical expressions.
a. $\llbracket \mathrm{II} \rrbracket^{k, j}=\operatorname{AUTH}(k)$.
b. 【now $\rrbracket^{k, j}=\operatorname{TIME}(k)$.

While the context is unaffected by modal operators, we argue that there exist (analogously) a set of context-shifting operators that are responsible for indexical shift. Cross-linguistic differences in indexicality are localized to the presence/absence of these operators, which overwrite coordinates of the context tuple with coordinates from the index tuple. Specifically, Zazaki indexical-shifting is the result of the operator $\mathrm{OP}_{\forall}$, which overwrites all of the coordinates of the context parameter with those of the index parameter, effectively erasing any information of the actual speech act. ${ }^{7}$

$$
\llbracket \mathrm{OP}_{\forall} \alpha \rrbracket^{k, j}=\llbracket \alpha \rrbracket^{j, j} .
$$

Such a move is possible only if the context and index parameter are elements of the same type, which is not the case in the standard theory. Thus, we enrich the index parameter so that it, like the context, keeps track of the reported utterance - its author, addressee, and location. ${ }^{8}$ In section 5.1 we will demonstrate that this move allows the welcome independent advantage of an elegant semantics of attitudes $d e$ se.

\subsection{Deriving Zazaki indexicality}

We posit that in the Zazaki lexicon, SAY can occur with $\mathrm{OP}_{\forall}$ as sister:

(26) 【say $\mathrm{OP}_{\forall} \alpha \rrbracket^{c, i}=\lambda x_{e} . \forall j$ compatible with what $\mathrm{x}$ says in $\mathrm{i},\left(\llbracket \mathrm{OP}_{\forall}[\alpha] \rrbracket^{c, j}\right)$

(27) $\llbracket \mathrm{OP}_{\forall}[\mathrm{I}$ am rich $] \rrbracket^{c ; j}=\llbracket[\operatorname{I}$ am rich $] \rrbracket^{j, j}=1$ iff. $\operatorname{AUTH}(j)$ is rich in $j$.

This proposal neatly captures the SHIFT-TOGETHER property of Zazaki: when any indexical shifts, they all must, since indexical shift is literal overwriting of the context parameter.

(28) ZAZAKI: John said to Bill that I am mad at you $\forall j$ compatible with what John says to Bill in i, [OP [I am mad at you] $]^{c, j}=$ $=\llbracket[\operatorname{Iam} \operatorname{mad}$ at you $] \rrbracket^{j, j}=1$ iff. $\operatorname{AUTH}(j)$ is $\operatorname{mad}$ at $\operatorname{ADDR}(j)$ in $j$

$=1$ iff. John is mad at Bill in $j$. 


\subsection{Deriving Slave first-person shift}

In Slave, the situation is different. Under the Slave verb hadi, only first person indexicals shift, as shown previously in example (17). We take this to be evidence for an additional context-shifting operator: $\mathrm{OP}_{\mathrm{AUTH}}$, which rewrites the author coordinate of the context parameter with that of the index parameter. Since AUTH(i) will be the counterpart of the attitude holder, the operator will set the author coordinate of the context parameter to the attitude holder.

$$
\begin{aligned}
& \llbracket \operatorname{OP}_{\mathrm{AUTH}} \alpha \rrbracket^{k, j}=\llbracket \mathrm{OP}_{\mathrm{ALTH}} \alpha \rrbracket^{\left.<A_{k}, H_{k}, l_{k}, t_{k}, w_{k}\right\rangle,\left\langle A_{j}, H_{j}, l_{j}, t_{j}, w_{j}\right\rangle}= \\
& =\llbracket \alpha \rrbracket^{\left\langle A_{j}, H_{k}, l_{k}, t_{k}, w_{k}\right\rangle,\left\langle A_{j}, H_{j}, l_{j}, t_{j}, w_{j}\right\rangle}
\end{aligned}
$$

(30) SLAVE: Simon said that you hit me with my slippers

$\forall j$ compatible with what Simon says in i,

[OP ${ }_{\text {AUTH }}\left[\right.$ [You hit me with my slippers] $\rrbracket^{<A_{c}, H_{c}, t_{c}, w_{c}>,\left\langle A_{j}, H_{j}, t_{j}, w_{j}\right\rangle}$

$=\llbracket[$ You hit me with my slippers $] \rrbracket^{\left\langle\mathbf{A}_{j}, H_{c}, t_{c}, w_{c}\right\rangle,\left\langle A_{j}, H_{j}, t_{j}, w_{j}\right\rangle}$

$=1$ iff. $\mathrm{H}_{c}$ hit $\mathrm{A}_{j}$ with the slippers belonging to $\mathrm{A}_{j}$ in $j$

$=1$ iff. $\operatorname{ADDR}\left(c^{*}\right)$ hit Simon with Simon's slippers.

Again, the SHIFT TOGETHER property of Slave 1st person indexicals, that they all refer to the same author, is captured.

\subsection{A Supported Prediction of the Operator Account: Multiple Embedding}

Recall that the theories of both Schlenker and von Stechow were also capable of handling the shift-together facts from Zazaki and Slave when combined with the clausemate-binding condition in (25). This constraint, while stipulative, has been independently argued to be active in the binding of long-distance anaphors in both Japanese (Iida 1996) and Chinese (Pan 1995), and hence seems preferable, perhaps, to the additional machinery we propose.

However, our operator-theoretic approach differs from the binding approaches of Schlenker and von Stechow in one crucial prediction. Recall from section 3 that shifting is process of value overwriting - within the scope of an $\mathrm{OP}_{\forall}$ operator, the original context coordinate values are lost. ${ }^{9}$ Thus, we predict that when an indexical shifts, indexicals below cannot "unshift" to pick up the utterance context. This is not predicted by the binding approaches, as the binding of something locally does not in principle prevent long-distance binding. ${ }^{10}$ Eliciting judgments on this requires a rather rich scenario.

Assume the following background information: Andrew is the brother of the famous traitor Rojda. Understandably, he keeps this knowledge secret from his new 
friends, Hesen and Ali. One day, Hesen finds out Andrew's secret and confronts him.

Below is a comic-strip of the following series of conversations between Andrew and Hesen, Andrew and Ali, and Andrew and a third-party. In (31a), Hesen confronts Andrew about his sister; Ali, flying by, happens to overhear Hesen's revelation. In (31b), Ali then proceeds to tell Andrew that he overheard what Hesen said.

(31) The sequence of events (as given in pseudo-glossed Zazaki)

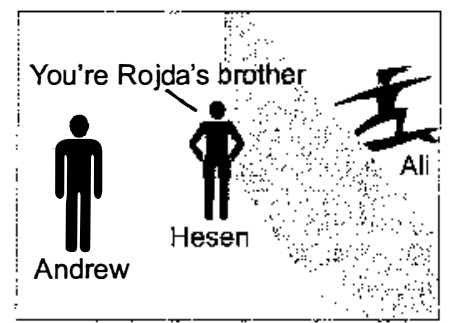

(i) Ali happens to overhear.

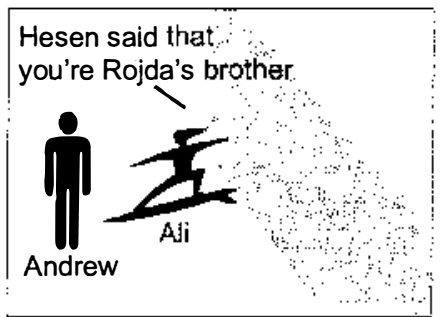

(ii) Ali then confronts Andrew.

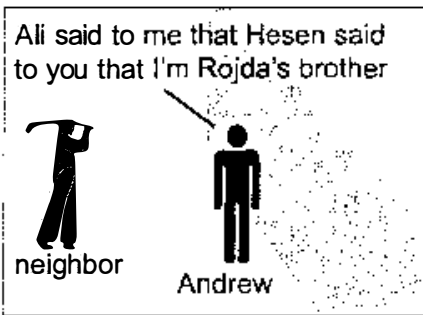

(iii) Andrew complains to his neighbor.

(31c) is the crucial target sentence for the scenario, where Andrew describes to his neighbor what Ali said.

(Andrew): $\mathrm{Ali}_{A} \mathrm{mi}_{U}$-ra va $\mathrm{ke} \quad \mathrm{H} \varepsilon \operatorname{seni}_{H}$ to ${ }_{U}$-ra va $\varepsilon_{\{H, A, * U\}}$ braye Ali me-to said that Hesen you-to said I brother

Rojda-o

Rojda-GEN

'Ali said to Andrew that Hesen said to Andrew that $\{$ Hesen, Ali, *Andrew is Rojda's brother.'

As indicated in the translation, (32) is not grammatical when Andrew is reporting what Ali said in (31b). This is precisely what our operator-theoretic account predicts, since shifted indexical to-ra "to you' (referring to Andrew, not the neighbor) diagnoses the presence of $\mathrm{OP}_{\forall}$, which prevents the further embedded $\varepsilon z$ 'I' from referring to the utterance author. Under this explanation, the ungrammaticality of (32) is a result of the shifting of the higher indexical. Indeed, when there is no shifted indexical in the intermediate clause, the lower indexical may pick up the, utterance context. Suppose instead that Ali overheard Hesen talking to some other person, Fatima, about Andrew's identity. Andrew could then report as follows: 
(33) (Andrew): $\mathrm{Ali}_{A} \mathrm{mi}_{U}$-ra va $\mathrm{k} \varepsilon \quad \mathrm{H} \varepsilon \operatorname{seni}{ }_{H}$ Fatima-ra va $\varepsilon \mathrm{z}_{\{H, A, U\}}$ braye Ali me-to said that Hesen Fatima-to said I brother

Rojda-o

Rojda-GEN

'Ali said to Andrew that Hesen said to Fatima that $\{$ Hesen, Ali, *Andrew $\}$ is Rojda's brother.'

Thus, the cases of double embedding of verbs-of-saying satisfy a surprising prediction made by the operator-theoretic approach: indexical reference to the utterance context is not universally available, but dependent on whether higher indexicals shift.

\section{Varying Lexical Entries for Different Shift Operators}

Under a pronoun-centric view of indexical shift (e.g. Schlenker (2003)), the nature of the attitude verb above the indexicals should not matter. However, in Slave the attitude verb can influence the behavior of embedded indexicals in two distinct ways. The first is with respect to the indexicals that are affected, and the second is with respect to the obligatoriness of the shifting. Thus, in Slave, certain attitude verbs shift both 1 st and 2 nd person, while others shift only 1 st person. This is indeed surprising if "all of the action in shifting" (i.e. the underspecified nature of the lexical entries) is localized to the pronouns themselves. Moreover, while certain attitude verbs always shift indexicals under them, others allow an indirect discourse reading.

These facts are readily explained (indeed, even predicted) if shifting is subject to the lexical combinatorics of attitude verbs and context-shifting operators. In an operator-theoretic account of indexical shift, the interpretation of indexicals should be entirely dependent of the embedding predicate. In English, of course, this is not the case:

a. John told Bill, you should buy it for me, not him

b. John wanted, you should buy it for me, not him

The facts in Slave are different, however. TELL shifts the 1st and 2nd persons to refer to the embedded context. On the other hand, SAY and WANT shift only the interpretation of the 1st person to the embedded context; surprisingly, the second person pronoun still refers to the addressee of the matrix utterance.

a. TELL: $\forall c$ compatible: ADDR(c) should buy it for AUTH(c), not $\mathbf{g}(\mathbf{4 2})$ 
b. WANT: $\forall c$ compatible: $\operatorname{ADDR}\left(\mathbf{c}^{*}\right)$ should buy it for AUTH(c), not $\mathbf{g ( 4 2 )}$

This behavior is exemplified in the following Slave sentences. In the first example, both embedded pronouns refer to the author and addressee in the embedded context, while in the second pair, only the embedded 1st person pronoun refers to the attitude holder.

(36) TELL: embedded $1 \mathrm{ST}$ and $2 \mathrm{ND}$ shift

[segha ráwo̧d’i] sédi̧di yilé

[1.sg-for 2.sg-will-buy] 2.sg-tell-1.sg PAST

'You sg. told me to buy it for you.'

(37) INTRANS. WANT: embedded 1sT shifts, but 2ND does not

a. sú [leshuyie k'eguhw'e] yerinewe

Q [spoon 1.sg-will-lick] 2.sg-want

Do you $\left[\operatorname{ADDR}\left(\mathrm{c}^{*}\right)\right]$ want to lick the spoon?

b. denexare [wojję] yeni̧we

sister [2.sg-will-sing] 3.sg-want

Sister wants you $\left[\operatorname{ADDR}\left(\mathrm{c}^{*}\right)\right]$ to sing.

The second respect in which the embedded predicates (and not the pronouns) determine the behavior of indexical shift is in terms of its optionality. Recall that in a pronoun-centric view, there is an underspecification implementation of the optionality of shifting. This would leave it impossible to express the fact that in one case, the pronoun must shift, while in another, such shifting is optional. Consider the following data:

a. WANT: optionally shifts indexicals in its complement

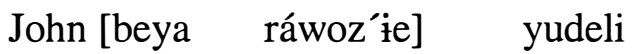

John [1.sg-son 3.sg-will-hunt] 3.sg-want-4.sg

John wants his son to go hunting. (direct)

John wants my son to go hunting. (indirect)

b. SAY: obligatorily shifts indexicals in its complement

Simon [rásereyineht'u] hadi

Simon [2.sg-hit-1.sg] 3.sg-say

Simon said that you hit $\left\{\right.$ him, ${ }^{*}$ me $\}$.

In Slave, different embedding predicates have different requirements: under WANT, 'I' is a piece of phonology that can be used to realize either AUTH(c) or AUTH(c*). 
On the other hand, under SAY, ' $\mathrm{I}$ ' is a piece of phonology that can only be used to realize AUTH(c). Importantly, these two predicates pattern together in shifting the first, but not second person, when they shift, but they diverge in that the latter attitude verb, but not the former, always requires an embedded interpretation. This state of affairs is not well-modelled by placing the locus of optionality in the specification of the pronouns.

However, on the operator-theoretic account, the behavior of indexical shift is entirely determined by the lexical entry of the embedding verb, which may have various lexical idiosyncrasies. We provide these for Slave as follows:

$\begin{array}{lll}\text { VERB } & \text { LEXICAL ENTRIES } & \text { CLASS DESCRIPTION } \\ \text { TELL } & {\left[\text { tell }\left(\mathrm{OP}_{\forall}\right)\right]} & \text { optionally shifts all person indexicals } \\ \text { WANT } & {\left[\text { want }\left(\mathrm{OP}_{\text {auth }}\right)\right]} & \text { optionally shifts 1st person indexicals } \\ \text { SAY } & {\left[\text { say }_{\mathrm{O}} \mathrm{P}_{\text {auth }}\right]} & \text { obligatorily shifts } 1 \text { st person indexicals }\end{array}$

\section{Context Coordinates: Further Considerations}

This section serves as preliminary comment on two important issues noted earlier in this paper. First, we argue that the enrichment of the index parameter we employed in section 3 allows an elegant treatment of attitudes de se and logophors, and hence is independently desirable. We then turn to apparent counterexamples of SHIFTTOGETHER from Amharic and English, and suggest areas in which they require further study.

\subsection{Possible evidence for an enriched index: de se and logophors}

One possible alternative to the implementation of context-shifting operators advanced here is to leave the index parameter a simple world-time pair and directly copy the arguments of the verb into the context parameter:

(40) 【J. say to B. OP $\forall \alpha \rrbracket^{c, i}=\forall j$ compatible with what J. says, $\llbracket \alpha \rrbracket^{<B i l l, J o h n, \ldots>, j}$

However, there exists evidence independent of the indexical shift facts that the index parameter does contain the author, addressee, and location parameters.

\subsubsection{Capturing de se attitudes}

In our proposal, the modal accessibility relation picks out indices where the AUTH coordinate is the individual that the speaker identifies as his counterpart. Thus, 
AUTH(i) is a de se referent. ${ }^{11}$ We propose that subject-controlled PRO actually denotes this coordinate: ${ }^{12}$

$$
\begin{aligned}
& \llbracket \mathrm{PRO}_{s u b j} \rrbracket^{c, i}=\mathrm{AUTH}(\mathrm{i}) \\
& \text { 【hope PRO to win } \rrbracket^{d, e}=\lambda \mathrm{x} . \forall \mathrm{f} \text { compatible with what } \mathrm{x} \text { hopes in e, } \llbracket \mathrm{PRO}_{s u b j}
\end{aligned}
$$

Similarly, object-controlled PRO is identified with ADDR(i) to capture the de te facts of object control (Chierchia 1989): ${ }^{13}$

(42) a. Thinking that she was Mary's mother, John begged of Mary, "Mary should sing."

b. \# John begged Mary to sing.

\subsubsection{Capturing logophors}

This technology also allows us to propose that logophoric pronouns denote coordinates of the index parameter as well (and are simply morphological spellouts of these).
a. 【LOG-auth $\rrbracket^{c, i}=\operatorname{AUTH}(\mathrm{i})$
b. 【LOG-addr $\rrbracket^{c, i}=\operatorname{ADDR}(\mathrm{i})$

This implicitly forces all logophors to be read $d e$ se, a prediction which Kusumoto (1998) has verified for Bafut, a Bantu language of Cameroon.

As it stands, however, treating logophors simply as, e.g., AUTH(i), has several technical problems. First, it allows logophoric elements to appear outside of attitude-embedded contexts, contrary to fact. We might avail ourselves of the following ill-understood stipulation:

(44) Context blocking: Do not use a logophor when an indexical could be used.

This blocks the use of logophors outside of attitude contexts. It also explains the absence of 1st person logophors in embedded contexts, since the indexical is still available (except under shifting).

Indeed, we seem to find surprising evidence for this in Mupun (Frajzyngier 1993), which has a ADDR-LOG (i.e. referring to reported speech addressee) that cannot co-refer with the utterance author: ${ }^{14}$

$$
\begin{aligned}
& \text { wu sat n-an nə gwar ta dar n-jos } \\
& 3 \text { m say prep-1sg Comp ADDR-LOG stop stay Jos } \\
& \text { *'He }{ }_{1} \text { told me that I stopped in Jos.' }
\end{aligned}
$$


The Mupun data confirm that LOG-addr cannot be used when an indexical could.

In sum, enrichment of the index parameter to include author, addressee, and location coordinates allows us to unify under a single rubric both attitudes de se and the semantics of logophoric elements. Though further work is clearly necessary to understand the source of the distributional constraints on the varieties of PRO and logophoric elements, the semantics offered here provides additional motivation for making the index parameter of the same type as the context.

\subsection{Even Shiftier Indexical Expressions in Amharic and English}

\subsubsection{Amharic}

Schlenker (2003) points out a case in Amharic that seems to counterexemplify the SHIFT-TOGETHER constraint.

$$
\begin{aligned}
& \text { aləttazzəzəññ } \\
& \text { 1st.sg.-FUT-NEG-obey-1st.sg. 3rd.sg.m-PAST-say } \\
& \text { 'John }{ }_{i} \text { said } \mathrm{I}_{i} \text { will not obey me.' (Leslau 1995) }
\end{aligned}
$$

However, we have preliminarily established an additional judgement for this sentence: it is unambiguous in a way Schlenker's system would not expect: it cannot mean $\mathrm{John}_{i}$ said that he $e_{i}$ will not obey me.

Further research is necessary to determine what the extent of such apparent violations of SHIFT-TOGETHER are in Amharic. ${ }^{15}$

\subsubsection{English temporal indexicals}

Schlenker also argues there are temporal indexicals in English that behave as though they can optionally shift.

(47) Over the past few years, John has repeatedly told me he would return my money in precisely two days. ${ }^{16}$

Given that utterance-indexical temporal adverbs (e.g., tomorrow) do not shift in these contexts, this would seem to argue against overwriting of the time coordinate of the context. Note, however, that in two days does not always show this shifting behavior, and that its shifting may depend on the temporal properties of the embedded clause, in contrast with the canonical temporal indexicals: ${ }^{17}$

(48) Last Saturday [May 8th], John said that he'd return in precisely eight days [May 16th/\#23rd]. 
(49) Last Saturday [May 8th], John said that he will return in precisely eight days [May \#16th/23rd].

The sensitivity of in two days to temporal operators casts doubt on its status as a bona fide indexical. According to Schlenker, in two days cannot pick up reference from the discourse context, unlike temporal anaphors (e.g., later or before):

(50) I met John a week ago. \{*In precisely two days, two days later $\}$ he was sick.

However, native speakers we have consulted do not agree that in two days is unacceptable in the example above. We thus conclude tentatively that in two days is actually anaphoric (albeit with possibly different anaphoric requirements than before), with the proviso that more careful study is necessary.

\section{Summary}

We have presented three new phenomena that must be addressed in any account of the interpretive possibilities of indexicals:

1. Shift-Together CONSTRAint: shiftable indexicals must shift together.

2. Within-language, the embedding verb can affect which indexicals shift and whether they must.

3. In cases of multiple embedding, shifting in the intermediate clause prevents a lower indexical from being interpreted indexical to the matrix context.

We accounted for these puzzles by proposing that (at least in Zazaki and Slave) indexical shifting is driven by context-shifting operators, which overwrite the context parameter of the interpretation function with the intensional index parameter:

CONTEXT-SHIFTING OPERATORS
a. Zazaki: $\llbracket \mathrm{OP}_{\text {all }}[\alpha] \rrbracket^{c, i}=\llbracket \alpha \rrbracket^{i, i}$
b. Slave: $\llbracket \mathrm{OP}_{\mathrm{AUTH}}[\alpha] \rrbracket<A_{c}, \ldots>, i=\llbracket \alpha \rrbracket^{<\dot{A}_{i}, \ldots>, i}$

\section{Acknowledgments}

Special thanks to our Zazaki informants, especially Gulcem Aktas, for giving thoughtful judgments on very intricate contexts. We have benefited from conversations with: Jon Gajewski, Kai von Fintel, Danny Fox, Anastasia Giannakidou, Irene Heim, Sabine Iatridou, Norbert Hornstein, Alee Marantz, Taisuke Nishigauchi, Barbara Partee, Chris Potts, Keren Rice, Norvin Richards, Peggy Speas, Arnim von Stechow, and the participants of the the MIT LF Reading Group. Research for 
the first author was partly supported by a Graduate Research Fellowship from the National Science Foundation. The authors' names are listed in alphabetical order.

${ }^{1}$ Zazaki, also known as Dimili, is an Indo-Iranian language spoken mostly in Turkey by $2-4$ million ethnic Kurds. The data reported here are elicited from fieldwork with four native speakers.

${ }^{2}$ Slave is in Athabaskan language spoken in the Northwest Territories of Canada. All data are from Rice (1986).

${ }^{3}$ The possibility of shifting seems limited to vano. Other attitude verbs (e.g., believe, think, dream), including those of verbal discourse (e.g., hear, yell) do not allow $\varepsilon z$ to shift:

(i) $\quad \operatorname{Hesen}_{j}$ termine $\mathrm{k} \varepsilon n o \mathrm{k} \varepsilon \quad \mathbf{\varepsilon z}_{* j / k}$ newesha

Hesen believe does that I sick.be-PRES

'Hesen believes that $\{\mathrm{I}$, *Hesen $\}$ is sick.

${ }^{4} \mathrm{~A}$ speech-context domain is the scope of a verb-of-saying up to the scope of the next c-commanded verb-of-saying.

${ }^{5}$ Although Schlenker (2003) cites data from Leslau (1995) suggesting that Amharic does not respect SHIFT-TOGETHER. See section 5.2.

${ }^{6}$ Strictly speaking, Schlenker assumes that all pronouns are free variables, and that the indexical content is presuppositional (as with the treatment of gender in Heim and Kratzer (1998)). This then requires an $\iota$-closure operation, which accomodates the presupposition. See Schlenker (2003) for details.

${ }^{7} \mathrm{OP} \forall$ is a n instance of Stalnaker's (1978) diagonal operator: $\Delta(\lambda c \lambda i \chi(c)(i)=\lambda c \chi(c)($ WORLD-TIME $(c))$

${ }^{8}$ Likewise, Stalnaker (1978) makes the same move.

${ }^{9}$ This logic is of course dependent on the structure of the context parameter; if it were a set-like object, information would not be lost underneath a context-shifting operator.

${ }^{10}$ It is possible that context-binding is subject to intervention effects. However, precise formalization of this is non-trivial, as cases where indexicals do not shift are analyzed as binding across attitude verbs, which are potential binders.

${ }^{11}$ Thanks to Kai von Fintel for pointing out both the importance of this question and the evidence from de $s e$ attitudes.

${ }^{12}$ This should recall the treatment of de se in the centered-world semantics of Cresswell (1985).

${ }^{13}$ Chierchia argues that several object control verbs (e.g., force) are not read obligatory de te. While we find such judgments difficult to evaluate, it should be noted that our account must minimally make a syntactic difference between subject-controlled and object-controlled PRO, as well one between control into complements and adjuncts (where the obligatory readings do not seem present). Chierchia's worries, which are related to these questions of the distribution of the various PROs, might be similarly solved.

${ }^{14}$ However, (44) may face difficulty in Aghem Hyman (1979), where AUTH-LOG can occur with a shifted 2nd-person pronoun; if this is to be consistent with SHIFT-TOGETHER, further research is clearly needed on possible logophor inventories.

${ }^{15}$ Danny Fox has suggested to us that perhaps Amharic has the option of raising indexicals covertly, while Slave and Zazaki do not. The unambiguous meaning of (46) might then follow from a subject-object asymmetry in extraction.

${ }^{16} \mathrm{We}$ use in precisely two days to attempt to control the durative period reading of in two days. Our informants have indicated that with precisely, the durative reading is dispreferred: 
(ii) John said he would finish the paper in (*precisely) two days, and in fact, he did, since he gave it to me after only a day.

${ }^{17}$ However, it is possible that all of this has to do with a double-access blocking effect. Indeed, it does seem possible to interpret in two days with intermediate temporal context when the matrix sentence is in the past:

(iii) Galois believed Nostradamus had predicted that the world would end in exactly two days, which is why he accepted the duel.

(iv) \# I've decided to stop worrying about my future because Nostradamus predicted that the world would end in exactly one week.

\section{References}

Chierchia, Gennaro. 1989. Anaphora and Attitudes De Se. R. Bartsch, J. van Benthem, and B. van Emde (eds.) Language in context. Dordrecht: Foris.

Cresswell, M. J. 1985. Structured meanings: The semantics of propositional attitudes. MIT Press.

Frajzyngier, Zygmunt. 1993. A grammar of Mupun. Dietrich Reimer Verlag.

Heim, I., and A. Kratzer. 1998. Semantics in generative grammar. Blackwell.

Hyman, Larry. 1979. Aghem Grammatical Structure. Southern California Occasional Papers in Linguistics 7.

Iida, Masayo. 1996. Context and binding in Japanese. CSLI.

Kaplan, David. 1977. Demonstratives. Themes from Kaplan (1999), 481-564. Oxford.

Kusumoto, Kiyomi. 1998. Tenses as logophoric pronouns. MIT/UConn/UMass Semantics Workshop.

Leslau, Wolf. 1995. A reference grammar of Amharic. Harrassowitz.

Pan, Haihua. 1995. Locality, self-ascription, discourse prominence, and Mandarin reflexives. Doctoral Dissertation, U. Texas at Austin.

Partee, B. 1973. The Syntax and Semantics of Quotation. S. A. Anderson and P. Kiparsky (eds.) A festschrift for Morris Halle.

Percus, Orin, and Uli Sauerland. 2002. Pronoun movement in dream reports. NELS 33.

Recanati, Francois. 1999. Oratio obliqua, oratio recta. MIT Press.

Rice, Keren. 1986. Some remarks on direct and indirect speech in Slave (Northern Athapaskan). F. Coulmas (ed.) Direct and indirect speech, 47-76. Mouton de Gruyter.

Schlenker, P. 1999. Semantic Uniformity: A Cross-categorial approach. Doctoral Dissertation, MIT.

Schlenker, P. 2003. A Plea for Monsters. Ling. and Phil. 26:29-120.

Speas, Margaret. 1999. Person and Point of View in Navajo. WCCFL 18.

Stalnaker, Robert. 1978. Assertion. Context and Content (1999). Oxford.

Stechow, A. v. 2002. Feature deletion under semantic binding: Tense, person, and mood under verbal quantifiers. NELS 33.

Zimmerman, Thomas Ede. 1991. Kontextabhängigkeit. A. von Stechow and D. Wunderlich (eds.) Semantik: ein internationales Handbuch der zeitgenössischen Forschung, 151-229. 